DOI: $10.5216 /$ cab.v13i3.14403

\title{
DIGESTIBILIDADE DA SOJA SEMI-INTEGRAL EXTRUSADA PARA LEITÕES NA FASE INICIAL
}

\author{
MARIA CRISTINA ThOMAZ ${ }^{1}$, ANTONIO CARLOS SILVEIRA ${ }^{2}$, ROdOLFo NASCIMENTO KRONKA ${ }^{1}$, SERGIO \\ NASCIMENTO KRONKA ${ }^{1}$, FÁBIO ENRIQUE LEMOS BUdIÑO ${ }^{3}$ \\ ${ }^{1}$ Professores Doutores da Faculdade de Ciências Agrárias e Veterinárias de Jaboticabal, Jaboticabal, SP, Brasil. \\ ${ }^{2}$ Professor Doutor da Faculdade de Medicina Veterinária e Zootecnia da UNESP, Botucatu, SP, Brasil \\ ${ }^{3}$ Pesquisador Doutor do Instituto de Zootecnia, Agência Paulista de Tecnologia dos Agronegócios, Nova Odessa, SP, Brasil. - \\ fbudino@iz.sp.gov.br
}

Com o objetivo de determinar os coeficientes de digestibilidade (CD) e os nutrientes digestíveis (ND) da soja semi-integral extrusada, foram conduzidos dois ensaios (Ensaio 1 - alimentação convencional e Ensaio 2 alimentação das porcas a partir de 109 dias de prenhez, na lactação e dos leitões lactentes e na fase inicial, com rações sem farelo de soja), subdivididos, cada um, em duas fases (32 e 50 dias de idade). Foram utilizados oito leitões em cada fase, desmamados aos 25 dias de idade. Foi utilizado o método da coleta total de fezes. No alimento e nas fezes analisaram-se matéria seca, proteína bruta, extrato etéreo, fibra bruta e energia bruta. Os seguintes valores médios foram obtidos: CDMS - 88,87\%; CDPB - 86,81\%; CDEE - 85,41\%; CDFB - 78,22\%;

CDEB - 80,21\% e CMED - 95,71\%, obtendo-se, assim, os valores médios para nutrientes digestíveis: MSD 81,28\%; PD - 34,49\%; EED - 14,02\%; FD - 4,49\%; EDa $4087,86 \mathrm{kcal} / \mathrm{kg}$ e EMa - 3912,73 kcal $/ \mathrm{kg}$. Os CD não foram afetados pela alimentação diferenciada das porcas e dos leitões ou pelas diferentes idades dos animais. Além disso, a soja semi-integral extrusada apresentou bons níveis de ND, principalmente no que se refere às energias digestível e metabolizável.

PALAVRAS-CHAVE: fontes proteicas; soja; suínos.

\section{DIGESTIBILITY OF EXTRUDED SEMI-WHOLE SOYBEAN FOR PIGLETS IN THE INITIAL PHASE}

\section{ABSTRACT}

Two assays were conducted to determine the coefficients of digestibility (CD) and the digestible nutrients (DN) of the extruded semi-whole soybean (Assay 1 - conventional feeding and Assay 2 - feeding for sows, starting at 109 days of pregnancy and during the lactation and for lactating piglets and in the initial phase, with rations without soybean meal). Each assay was divided into two phases (32 and 50 days of age). Eight piglets weaned at 25 days of age were used. Total feces collection method was used. The following variables were analyzed in feed and in feces: dry matter, crude protein, ether extract, crude fiber and gross energy. The following average values were obtained: CDDM - 88.87\%; CDCP - 86.81\%; CDEE 85.41\%; CDCF - 78.22\%; CDGE - 80.21\% and CMDE $95.71 \%$, which allowed the calculation of the digestible nutrients: DDM - 81.28\%; DP - 34.49\%; DEE - 14.02\%; DF - 4.49\%; DEa - $4087.86 \mathrm{kcal} / \mathrm{kg}$ and MEa - 3912.73 $\mathrm{kcal} / \mathrm{kg}$. The different coefficients of digestibility were not affected by the differential feeding for sows and piglets nor by the different ages of the animals. Moreover, the extruded semi-whole soybean presented good levels of $\mathrm{DN}$, concerning mainly the digestible and metabolizable energy.

KEYWORDS: protein sources; soybean; swine. 


\section{INTRODUÇÃO}

$\mathrm{O}$ pequeno crescimento dos leitões, particularmente daqueles desmamados com quatro semanas de idade ou menos, está associado com pequena ingestão de alimento e baixa digestibilidade de energia e proteína. Isto frequentemente resulta em um déficit de energia com perda da gordura corporal logo após a desmama.

Um dos motivos para que isto ocorra, é o fato de o sistema digestivo dos leitões ainda não se encontrar totalmente desenvolvido, sendo, então, incapaz de digerir satisfatoriamente os ingredientes que normalmente compõem a ração, principalmente aqueles de origem vegetal (BERTOL et al., 2001).

Por essa razão, a incorporação de produtos lácteos às rações de leitões recém-desmamados tem resultado em melhores ganho de peso e conversão alimentar, sugerindo, portanto, uma melhor digestibilidade. Entretanto, em função dos altos custos desses produtos, alternativas de substituição vêm sendo estudadas, desde que não afetem o desempenho e a utilização dos nutrientes (SOHN et al., 1994).

As restrições impostas às fontes proteicas de origem animal na nutrição animal pelo mercado internacional e, em menor grau, pelo mercado interno, geraram uma demanda extra do farelo de soja. O grão de soja, por ser um vegetal com elevados teores de proteína e energia, constitui boa alternativa de alimento proteico, apresentando cerca de $17 \%$ a $18 \%$ de óleo e $35 \%$ a $37 \%$ de proteína bruta de elevado valor biológico, com composição em aminoácidos essenciais favorável à alimentação de aves e suínos (BELLAVER et al., 2002). Já a soja semi-integral extrusada, como resultado do processo da extração parcial do óleo, apresenta $9,0 \%$ a 10,0\% de extrato etéreo e $44 \%$ a $46 \%$ de proteína bruta, podendo ser suplemento energético-proteico na formulação de rações (CASTILLO et al., 2001).

Desde que é sabido que o farelo de soja, principal fonte de proteína das rações de suínos, além de causar problemas digestivos aos leitões recém-desmamados, é pobre em óleo (menos de $1 \%$ ), a adição de fontes de gordura tem se tornado frequente, pois não é possível atender as exigências dos animais de outra forma (TURLINGTON et al., 1990).

Por outro lado, os resultados são conflitantes quanto à adição de gordura às rações de leitões. Aumentos no ganho de peso e melhor conversão alimentar foram observados por ATTEH \& LEESON (1983). Resultados contrários, no entanto, foram encontrados por CERA et al. (1988b).
Essas diferenças podem ser resultado de alguns fatores que influenciam a resposta dos animais à adição de gordura, tais como: absorção de um ácido graxo podendo interferir com a de outro, ponto de fusão, relação energia:aminoácidos, idade dos leitões e tipo ou concentração da gordura adicionada (CERA et al., 1988a).

Sendo assim, as sojas integral ou semiintegral surgiram como alternativas, pois, além de constituírem excelentes fontes de proteína e aumentarem o conteúdo energético da dieta, eliminam o custo da extração do óleo. Porém, a digestibilidade do óleo extraído é maior, tendo em vista que o não extraído está encapsulado na membrana celular, tornando-se menos susceptível à digestão (ADAMS \& JENSEN, 1984).

Apesar de a soja crua possuir um alto teor de óleo, ela é rica em fatores antinutricionais, os quais impedem sua utilização, principalmente para monogástricos (BERTOL et al., 2001).

MOREIRA et al. (1994) afirmaram ser importante considerar que os tipos (extrusão, micronização, tostagem ou jet sploder) e os parâmetros (temperatura, umidade, pressão e tempo de aquecimento) do processamento influenciam o valor nutricional da soja e que a idade do suíno também tem efeito sobre o valor energético do ingrediente.

Dessa forma, foram conduzidos dois ensaios com o objetivo de determinar os coeficientes de digestibilidade e os nutrientes digestíveis da soja semi-integral extrusada, para leitões em diferentes idades na fase inicial e criados até a desmama com ou sem contato com o farelo de soja.

\section{MATERIAL E MÉTODOS}

Os dois ensaios foram conduzidos no Setor de Suinocultura do Departamento de Zootecnia da Faculdade de Ciências Agrárias e Veterinárias da UNESP/Campus de Jaboticabal. Em cada ensaio foram utilizados oito leitões mestiços (Landrace $\mathrm{x}$ Large White), machos castrados, desmamados aos 25 dias de idade. Ambos os ensaios foram subdivididos em duas fases. A primeira fase iniciada quando os animais estavam com 32 dias de idade $(9,3 \mathrm{~kg}$ de peso médio) e a segunda quando os mesmos animais estavam com 50 dias de idade $(12,7 \mathrm{~kg}$ de peso médio).

Os ensaios foram conduzidos na unidade de digestibilidade, que é construída em alvenaria, fechada lateralmente com paredes de $1,80 \mathrm{~m}$ e o restante $(0,70 \mathrm{~m})$ protegido com cortina plástica, contendo oito gaiolas de metabolismo semelhantes às 
descritas por PEKAS (1968).

No primeiro ensaio, os leitões lactentes receberam a mesma dieta oferecida às porcas (com farelo de soja na composição). Logo após a desmama, passaram a receber ração inicial contendo também farelo de soja em sua composição (Tabela 1). Essa mesma dieta foi utilizada como referência nas duas fases (aos 32 e 50 dias de idade). Os animais foram alojados nas gaiolas de metabolismo por 12 dias em cada ensaio, sendo os primeiros sete para adaptação às gaiolas e às rações e os cinco restantes para a coleta de fezes e urina.

Nas duas fases, a soja semi-integral extrusada (SSIE) substituiu, na base da matéria natural, $30 \%$ da ração referência, formulada para atender as exigências dos animais no período (NRC,
1998), formando a dieta "teste". Quatro leitões receberam a ração referência e outros quatro, a ração teste. Os resultados das análises de composição química e valores energéticos das rações referência, teste e da SSIE encontram-se na Tabela 2.

As rações foram fornecidas à vontade em duas refeições diárias (às 8:00h e 16:00h), sendo a quantidade total, fixada de acordo com o consumo na fase de adaptação, baseada no peso metabólico $\left(\mathrm{kg}^{0,75}\right)$. Após cada refeição, a água foi fornecida, no mesmo local da ração, à base de $3 \mathrm{~mL} / \mathrm{g}$ de alimento ingerido.

Foi utilizado o método da coleta total de fezes, adicionando-se $2 \%$ de óxido férrico $\left(\mathrm{Fe}_{2} \mathrm{O}_{3}\right)$ às rações como marcador fecal, para definir o início e o final da coleta.

Tabela 1 - Composição percentual e valores calculados das rações utilizadas nos ensaios 1 e 2

\begin{tabular}{|c|c|c|c|}
\hline \multirow[t]{2}{*}{ Ingredientes $(\%)$} & \multicolumn{2}{|c|}{ Ração Referência } & \multirow{2}{*}{$\begin{array}{c}\mathrm{RM}^{(1)} \\
\text { Ensaio } 2\end{array}$} \\
\hline & Ensaio 1 & Ensaio 2 & \\
\hline Milho & 66,02 & 54,71 & 66,26 \\
\hline Farelo de soja & 21,19 & -- & -- \\
\hline Leite desnatado em pó & -- & 23,87 & -- \\
\hline Soro de leite & -- & 7,66 & -- \\
\hline Glúten & -- & 4,00 & -- \\
\hline Levedura seca & -- & 7,00 & -- \\
\hline Farelo de trigo & -- & -- & 13,80 \\
\hline Soja integral extrusada & -- & -- & 13,13 \\
\hline Farinha de carne & 3,50 & -- & 5,35 \\
\hline Farinha de peixe & 3,00 & -- & -- \\
\hline Fosfato bicálcico & 0,06 & 0,82 & -- \\
\hline Calcário calcítico & 0,13 & 0,72 & 0,49 \\
\hline Suplemento mineral ${ }^{(2)}$ & 0,24 & 0,24 & 0,24 \\
\hline Suplemento vitamínico ${ }^{(2)}$ & 0,40 & 0,40 & 0,22 \\
\hline Sal comum & 0,50 & 0,50 & 0,50 \\
\hline Antioxidante (BHT) & 0,01 & 0,01 & 0,01 \\
\hline Açúcar & 3,00 & -- & -- \\
\hline Óleo de soja & 1,81 & -- & -- \\
\hline L-Lisina.HCl (78\%) & 0,14 & 0,07 & -- \\
\hline \multicolumn{4}{|l|}{$\underline{\text { Valores Calculados }}$} \\
\hline Energia digestível (kcal/kg) & -- & 3471,79 & -- \\
\hline Energia metabolizável (kcal/kg) & 3272,57 & -- & 3206,15 \\
\hline Proteína bruta (\%) & 18,14 & 18,21 & 15,43 \\
\hline Lisina $(\%)$ & 1,03 & 1,03 & 0,82 \\
\hline Cálcio (\%) & 0,75 & 0,75 & 0,91 \\
\hline Fósforo total (\%) & 0,65 & 0,65 & 0,71 \\
\hline
\end{tabular}

(1) Ração Matrizes, oferecida dos 109 dias de gestação até a desmama, com acesso dos leitões lactentes utilizados no segundo ensaio;

${ }^{\text {(2) }}$ Suplemento vitamínico - Níveis de garantia por kg de produto: vit A 4.000.000 U.I; vit D-3 1.000.000 U.I; vit E 10.000 mg; vit K-

$33.000 \mathrm{mg}$; vit $\mathrm{B}_{12} 9.000 \mu \mathrm{g}$; vit $\mathrm{B}_{2} 3.800 \mathrm{mg}$; biotina $40 \mathrm{mg}$; pantotenato de cálcio $6.000 \mathrm{mg}$; niacina $14.000 \mathrm{mg}$; colina $100 \mathrm{~g}$; antibiótico $150 \mathrm{~g}$; antioxidante $60 \mathrm{~g}$; veículo q.s.p. $1.000 \mathrm{~g}$.

Suplemento mineral - Níveis de garantia por kg de produto: ferro $40.000 \mathrm{mg}$; cobre $35.000 \mathrm{mg}$; manganês $20.000 \mathrm{mg}$; zinco 40.000 $\mathrm{mg}$; cobalto $360 \mathrm{mg}$; iodo $840 \mathrm{mg}$; selênio $120 \mathrm{mg}$; veículo q.s.p $1.000 \mathrm{~g}$. 
A urina foi recolhida em baldes plásticos contendo $20 \mathrm{~mL}$ de $\mathrm{HCl}(12 \mathrm{~N})$ 1:1, para evitar perda de nitrogênio e proliferação bacteriana. Esses baldes foram colocados sob o funil coletor da gaiola, o qual foi recoberto com lã de vidro para a retenção de impurezas, como resíduos fecais ou de ração e cerdas dos animais. Diariamente, às 7:00h, foi feita a coleta de amostra, quando o conteúdo do balde era levado à uma proveta e o volume completado com água destilada para 2 litros, valor constante para todos os animais das duas fases.

Tabela 2 - Composição química e valores energéticos das rações referência (RR), teste e da SSIE utilizadas nos ensaios 1 e 2

\begin{tabular}{lccccc}
\hline \multicolumn{7}{c}{ Rações } & Ensaio 2 & SSIE \\
\hline Nutrientes & \multicolumn{2}{c}{ Ensaio 1 } & RR & Teste & \\
& RR & Teste & RR & 91,46 \\
Matéria seca (\%) & 89,21 & 90,23 & 89,48 & 90,11 & 39,72 \\
Proteína bruta (\%) & 18,39 & 26,39 & 18,22 & 23,89 & 5,12 \\
Matéria mineral (\%) & 5,46 & 5,03 & 5,08 & 5,18 & 16,41 \\
Extrato etéreo (\%) & 5,32 & 8,78 & 3,13 & 6,78 & 6,31 \\
Fibra bruta (\%) & 3,68 & 4,55 & 2,55 & 3,98 & 5097,10 \\
Energia bruta (kcal/kg) & 4032,10 & 4448,90 & 3802,40 & 4147,60 & \\
\hline
\end{tabular}

O conteúdo da proveta foi homogeneizado, sendo retirada alíquota de $200 \mathrm{~mL}$, a qual foi colocada em garrafas plásticas devidamente identificadas e mantidas em refrigerador $\left(3-4^{\circ} \mathrm{C}\right)$ para posterior análise laboratorial.

Diariamente, às $8: 15 \mathrm{~h}$, as fezes totais produzidas por animal foram coletadas em sacos plásticos identificados e armazenados a $-18^{\circ} \mathrm{C}$.

Terminado o período de coleta, uma amostra $(300 \mathrm{~g})$ das fezes foi homogeneizada, pesada e colocada em estufa com ventilação forçada a $55^{\circ} \mathrm{C}$ por $48 \mathrm{~h}$. Após a secagem e equilíbrio com a umidade do meio ambiente, foram novamente pesadas, moídas e enviadas para análise.

Quanto à urina, foram retirados $50 \mathrm{~mL}$ de cada amostra, colocados em placas de petri e levados à estufa com ventilação forçada e a temperatura de $50^{\circ} \mathrm{C}$ por $24 \mathrm{~h}$. Após esse período, adicionou-se mais $50 \mathrm{ml}$, retornando-as à estufa por mais $24 \mathrm{~h}$, sendo o material seco, então, enviado ao laboratório.

Matéria seca, proteína bruta, extrato etéreo, fibra bruta, matéria mineral e energia bruta foram analisados nas fezes e ração. Energia bruta foi analisada na urina.

$\mathrm{O}$ coeficiente de digestibilidade da matéria seca (CDMS); coeficiente de digestibilidade da proteína bruta (CDPB); coeficiente de digestibilidade do extrato etéreo (CDEE); coeficiente de digestibilidade da fibra bruta (CDFB); coeficiente de digestibilidade da energia bruta (CDEB) e coeficiente de metabolizabilidade da energia digestível (CMED), os quais permitiram o cálculo dos nutrientes digestíveis, foram obtidos de acordo com o método de MATTERSON et al. (1965).

A metodologia utilizada no ensaio 2 foi idêntica à do ensaio 1, diferindo apenas no fato de que as porcas, a partir de 109 dias de prenhez, na lactação, e os leitões lactentes, receberam dieta sem farelo de soja (Tabela 1). Durante a fase pré-inicial, os leitões receberam a mesma ração fornecida às porcas. Essa prática de alimentação diferenciada a partir do final da prenhez teve como finalidade limitar a transferência passiva de anticorpos anti-soja da porca para os leitões através do colostro (LI et al., 1991). Na fase inicial, passaram a receber ração que também não continha farelo de soja (Tabela 1), que foi a mesma utilizada como ração referência nas duas fases do ensaio. A composição química e os valores energéticos das rações referência, teste e SSIE encontram-se na Tabela 2.

Neste ensaio, os animais foram alojados nas gaiolas com 32 dias $(10,0 \mathrm{~kg}$ de peso médio) na primeira fase e 50 dias de idade $(12,8 \mathrm{~kg}$ de peso médio) na segunda fase.

O delineamento experimental utilizado, para os dois ensaios, foi o inteiramente ao acaso em esquema fatorial $2 \times 2$ ( 2 ensaios $\times 2$ fases), com 4 repetições. As análises foram realizadas de acordo com STEEL \& TORRIE (1980).

Para as análises estatísticas utilizou-se o seguinte modelo matemático:

$$
Y i j=\mu+\alpha i+\beta j+(\alpha \beta) i j+e i j
$$


Em que: na fase $\mathrm{j}$;

Yij = valor observado para o experimento $\mathrm{i}$,

$\mu=$ média geral;

$\alpha \mathrm{i}=$ efeito do experimento $\mathrm{i}(\mathrm{i}=1$ e 2 );

$\beta \mathrm{j}=$ efeito da fase $\mathrm{j}(\mathrm{j}=1$ e 2);

$(\alpha \beta) i j=$ efeito da interação entre $\mathrm{o}$ experimento $\mathrm{i}$ e a fase $\mathrm{j}$;

eij $=$ efeito do acaso.

\section{RESULTADOS E DISCUSSÃO}

Os resultados obtidos para $\mathrm{CD}$ dos nutrientes da soja semi-integral extrusada (SSIE), nos diferentes experimentos e fases, encontram-se na Tabela 3, enquanto os resultados das análises de variância, na Tabela 4.

Tabela 3 - Coeficientes de digestibilidade (CD \%) e coeficiente de metabolizabilidade (CM) da SSIE nos diferentes ensaios e fases

\begin{tabular}{lccccccc}
\hline \multirow{2}{*}{ CD (\%) } & \multicolumn{5}{c}{ Ensaio 1 } & Ensaio 2 \\
\cline { 2 - 7 } & Fase 1 $^{(\mathbf{1})}$ & Fase 2 $^{(\mathbf{2})}$ & Média & Fase 1 $^{(\mathbf{1})}$ & Fase 2 & Média & Média geral \\
\hline MS & 86,52 & 88,32 & 87,42 & 89,80 & 90,82 & 90,31 & 88,87 \\
PB & 87,29 & 88,22 & 87,76 & 85,73 & 86,00 & 85,86 & 86,81 \\
EE & 84,52 & 86,23 & 85,38 & 84,40 & 86,47 & 85,44 & 85,41 \\
FB & 77,09 & 79,47 & 78,28 & 78,01 & 78,28 & 78,15 & 78,22 \\
EB & 77,74 & 79,05 & 78,40 & 82,58 & 81,43 & 82,01 & 80,21 \\
CMED & 94,52 & 96,52 & 95,52 & 95,89 & 95,90 & 95,90 & 95,71 \\
\hline
\end{tabular}

(1) 32 dias de idade.

(2) 50 dias de idade.

Notou-se que, para os animais do Ensaio 1, o CDMS $(87,42 \%)$ foi menor $(\mathrm{P}<0,01)$ do que para aqueles do Ensaio 2 (90,31\%), enquanto que não houve efeito $(\mathrm{P}>0,05)$ das fases (Tabela 4), sugerindo que esses resultados foram influenciados, na verdade, pela retirada do farelo de soja da ração das porcas e dos leitões e não pela idade dos animais. $\mathrm{O}$ valor médio de CDMS (Tabela 3), obtido nestes ensaios $(88,87 \%)$ para animais de 32 ou 50 dias de idade, foi menor do que $89,30 \%$ (HANCOCK et al., 1990) e 90,30\% (FRIESEN et al., 1993), ambos trabalhando com leitões de 35 dias de idade. Foi maior, no entanto, do que $83,30 \%$ (HANCOCK et al., 1991) e 84,10\% (ENRIGHT et al., 1993) para leitões com 35 dias de idade e 85,70\% (HENRIQUE et al., 1997) para leitões com 47 dias de idade. MOREIRA et al. (1994), ao trabalharem com leitões de 21 dias e três tipos de sojas integrais extrusadas (A, B e C), verificaram CDMS de 83,50\%, 90,81\% e 91,57\%, respectivamente. Mais recentemente, MENDES et al (2004) observaram CDMS da SSIE de $81,85 \%$ para suínos na faixa de $38 \mathrm{~kg}$.

Tabela 4 - Resultados das análises de variância para os CD (\%) e CM (\%) dos nutrientes da SSIE

\begin{tabular}{lcclllc}
\hline Fatores & MS & PB & EE & FB & EB & ED $^{(1)}$ \\
\hline Ensaio (E) 1 & $87,42 b^{(2)}$ & $87,76 \mathrm{a}$ & $85,38 \mathrm{a}$ & $78,28 \mathrm{a}$ & $78,40 \mathrm{~b}$ & $95,52 \mathrm{a}$ \\
Ensaio (E) 2 & $90,31 \mathrm{a}$ & $85,86 \mathrm{~b}$ & $85,44 \mathrm{a}$ & $78,15 \mathrm{a}$ & $82,01 \mathrm{a}$ & $95,90 \mathrm{a}$ \\
Fase(F) $1^{(3)}$ & $88,16 \mathrm{a}$ & $86,51 \mathrm{a}$ & $84,46 \mathrm{~b}$ & $77,55 \mathrm{a}$ & $80,16 \mathrm{a}$ & $95,21 \mathrm{a}$ \\
Fase(F) 2 & $89,57 \mathrm{a}$ & $87,11 \mathrm{a}$ & $86,35 \mathrm{a}$ & $78,88 \mathrm{a}$ & $80,24 \mathrm{a}$ & $96,21 \mathrm{a}$ \\
\hline Teste F: & \multicolumn{7}{c}{} & & \\
\hline E & $9,45^{* *}$ & $11,38^{* *}$ & $0,01^{\text {ns }}$ & $0,27^{\text {ns }}$ & $25,50^{* *}$ & $0,37^{\text {ns }}$ \\
F & $2,26^{\text {ns }}$ & $1,16^{\text {ns }}$ & $9,41^{* *}$ & $2,54^{\text {ns }}$ & $0,12^{\text {ns }}$ & $2,63^{\text {ns }}$ \\
Ex F & $0,17^{\text {ns }}$ & $0,35^{\text {ns }}$ & $0,88^{\text {ns }}$ & $1,62^{\text {ns }}$ & $2,95^{\text {ns }}$ & $2,60^{\text {ns }}$ \\
\hline CV $(\%)$ & 2,11 & 1,29 & 1,44 & 2,12 & 1,78 & 1,29 \\
\hline
\end{tabular}

(1) Coeficiente de metabolizabilidade;

(2) Dentro de cada fator (E ou F), médias seguidas de letras iguais na coluna não diferem pelo teste $\mathrm{F}(\mathrm{P}>0,05)$;

${ }^{\text {(3) }}$ Média dos dois experimentos. 
O resultado obtido para CDPB (Tabela 4) nos animais do Ensaio $1(87,76 \%)$ foi maior $(\mathrm{P}<0,01)$ do que o observado naqueles do Ensaio 2 $(85,86 \%)$, demonstrando que a modificação na ração das porcas e dos leitões influenciou, de forma negativa, a digestibilidade da proteína da SSIE. Isso talvez possa ser explicado em função desses leitões terem recebido ração sem farelo de soja (Tabela 1), durante todo o período dos experimentos, não tendo, portanto, apresentado adaptação do sistema enzimático à hidrólise da proteína desse produto. No caso dos leitões estarem adaptados à proteína da soja, resposta diferente seria esperada, em virtude da desnaturação das proteínas, atribuída ao processamento por extrusão, aumentando sua susceptibilidade à hidrólise enzimática (MENDES et al., 2004).

Quanto à idade, não foi observada diferença ( $\mathrm{P}>0,05)$. O resultado médio para CDPB $(86,81 \%)$ obtido nos ensaios (Tabela 3) foi maior do que $80,60 \%$ para leitões de 35 dias (HANCOCK et al., 1991), 84,25\% para leitões de 21 dias (Moreira et al., 1994) e $85,90 \%$ para leitões de $4,7 \mathrm{~kg}$ (ENRIGHT et al., 1993), sendo muito semelhante a $86,80 \%$ para leitões de 16,9 kg (ADAMS \& JENSEN, 1985) e 86,12\% para leitões de $38 \mathrm{~kg}$ (MENDES et al., 2004). Entretanto, foi menor do que $89,00 \%$ para leitões de 35 dias (FRIESEN et al., 1993) e 87,32\% para leitões de 47 dias (HENRIQUE et al., 1997).

Quanto ao CDEE, foi observada resposta contrária aos dois nutrientes discutidos anteriormente, ou seja, não foi encontrada diferença ( $\mathrm{P}>0,05)$ entre os Ensaios 1 e 2 (Tabela 4), demonstrando que a alimentação diferenciada das porcas e dos leitões não influenciou a digestão desse nutriente. Notou-se, no entanto, efeito significativo $(\mathrm{P}<0,01)$ para as fases, indicando que, nos animais com 50 dias $(86,35 \%)$, a digestibilidade do óleo foi melhor do que com 32 dias de idade (84,46\%). Esses resultados concordaram com aqueles verificados por CERA et al. (1988c), que observaram elevação na digestibilidade do extrato etéreo com o aumento da idade dos leitões. TOKACH et al. (1989) observaram efeito benéfico da adição de óleo às rações somente a partir da terceira semana após a desmama. $\mathrm{O}$ valor médio de CDEE (85,41\%) obtido nestes ensaios (Tabela 3) foi maior do que o observado por LI et al. (1990) para o óleo de soja extraído $(80,10 \%)$, indicando que o processo de extrusão tornou o óleo contido na soja bastante digestível para os leitões. Foi maior também do que os valores observados para soja extrusada B $(76,98 \%)$, verificados por MOREIRA et al. (1994) para leitões de 21 dias, e por MENDES et al. (2004), que observaram valor de
81,48\% para SSIE em suínos de $37 \mathrm{~kg}$. Valor semelhante foi encontrado por MOREIRA et al. (1994), para soja A $(85,50 \%)$. Coeficientes maiores, no entanto, foram obtidos por MOREIRA et al. (1994) com a soja C $(96,37 \%)$ e HENRIQUE et al. (1997), trabalhando com leitões de 47 dias de idade $(98,78 \%)$.

Para CDFB, observou-se (Tabela 4) que nem a alimentação diferenciada das porcas e dos leitões (Ensaios) nem as diferentes idades (Fases) o afetaram $(\mathrm{P}>0,05)$. $\mathrm{O}$ valor médio observado $(78,22 \%)$ nos ensaios (Tabela 3$)$ foi menor do que $84,41 \%$ e $81,78 \%$, obtidos por MOREIRA et al. (1994) para leitões de 21 dias, para as sojas extrusadas A e B, respectivamente, e 80,14\% encontrado por HENRIQUE et al. (1997) para leitões de 47 dias. Foi maior, no entanto, do que $73,20 \%$ (soja extrusada C) obtido por MOREIRA et al. (1994).

Quanto ao CDEB, notou-se que foi maior $(\mathrm{P}<0,01)$ para os animais do Ensaio $2(82,01 \%)$, com relação àqueles do Ensaio 1 (78,48\% - Tabela 4), demonstrando que o aproveitamento da energia da dieta foi maior nos animais com alimentação diferenciada. A idade, porém, não afetou $(\mathrm{P}>0,05)$ esse parâmetro. O valor médio obtido $(80,21 \%$ Tabela 3) foi menor do que $81,95 \%, 86,87 \%$ e $91,06 \%$ (sojas A, B e C, respectivamente) para leitões com 21 dias (MOREIRA et al., 1994), 86,19\% para leitões com 47 dias (HENRIQUE et al., 1997) e 83,59\% para leitões de $37 \mathrm{~kg}$ (MENDES et al., 2004). O baixo CDEB obtido para a soja em estudo pode estar relacionado ao conteúdo de fibra bruta $(6,31 \%)$, pois sabe-se que, a cada $1,00 \%$ de aumento no nível de fibra da dieta, diminui em $3,50 \%$ a digestibilidade da energia bruta (NRC, 1998). MOREIRA et al. (1994) observaram $6,07 \%$ de fibra bruta na soja extrusada A de seu estudo, sendo essa inclusive a que apresentou o menor CDEB (81,95\%) em relação às sojas B e C. Já MENDES et al. (2004) observaram valor de 9,10\% de FB na SSIE que estudaram.

Com relação ao CMED, não houve efeito $(\mathrm{P}>0,05)$ para experimentos ou fases (Tabela 4), mostrando que nem a alimentação diferenciada ou a idade influenciaram esse parâmetro. O valor médio observado (Tabela 3) nos ensaios $(95,71 \%$ ) foi inferior a $96,53 \%$ encontrado por HENRIQUE et al. (1997), embora esteja dentro dos limites $(94,00 \%$ a 97,00\%) citados pelo NRC (1998).

Com base nos resultados apresentados nas Tabelas 2 e 3, foram calculados os valores de matéria seca digestível (MSD), proteína digestível (PD), extrato etéreo digestível (EED), fibra digestível 
(FD), energia digestível aparente (EDa) e energia metabolizável aparente (EMa), os quais encontramse na Tabela 5.

É importante observar que a soja extrusada em estudo é semi-integral (16,41\% de extrato etéreo) contra $18,00 \%$ a $20,00 \%$ de extrato etéreo da integral, com a qual praticamente todos os autores citados trabalharam, com exceção feita a MOREIRA et al. (1994), que, ao estudarem a soja extrusada B, encontraram $15,58 \%$ de EE. Porém, utilizaram ração referência contendo farelo de soja, o que permitiria comparar os valores obtidos para nutrientes digestíveis apenas do Ensaio 1, Média 1. Sendo assim, verificou-se que os valores encontrados neste experimento (Tabela 5) para MSD (79,96\%), FD $(4,94 \%), \quad \mathrm{EDa} \quad(3995,84 \mathrm{kcal} / \mathrm{kg}) \quad$ e $\mathrm{EMa}$ $(3817,16 \mathrm{kcal} / \mathrm{kg})$ foram menores do que $80,47 \%$, $5,42 \%, \quad 4240,00 \quad \mathrm{kcal} / \mathrm{kg} \quad$ e $3898,00 \mathrm{kcal} / \mathrm{kg}$, respectivamente, enquanto valores maiores foram obtidos para PD $(34,86 \%)$ e EED $(14,01 \%)$, quando comparados aos encontrados $(33,80 \%$ e $12,10 \%$, respectivamente) por MOREIRA et al. (1994).

Tabela 5 - Nutrientes digestíveis (ND) da SSIE

\begin{tabular}{|c|c|c|c|c|c|c|c|}
\hline \multirow{2}{*}{ ND } & \multicolumn{3}{|c|}{ Ensaio 1} & \multicolumn{3}{|c|}{ Ensaio 2} & \multirow[b]{2}{*}{ Média geral } \\
\hline & Fase $1^{(\mathbf{1})}$ & Fase $2^{(2)}$ & Média & Fase $1^{(\mathbf{1})}$ & Fase $2^{(2)}$ & Média & \\
\hline MSD (\%) & 79,13 & 80,78 & 79,96 & 82,13 & 83,06 & 82,60 & 81,28 \\
\hline $\mathrm{PD}(\%)$ & 34,67 & 35,04 & 34,86 & 34,05 & 34,16 & 34,11 & 34,49 \\
\hline $\operatorname{EED}(\%)$ & 13,87 & 14,15 & 14,01 & 13,85 & 14,19 & 14,02 & 14,02 \\
\hline $\mathrm{FD}(\%)$ & 4,86 & 5,01 & 4,94 & 4,92 & 4,94 & 4,93 & 4,94 \\
\hline EDA (kcal/kg) & 3962,41 & 4029,26 & 3995,84 & 4209,19 & 4150,57 & 4179,88 & 4087,86 \\
\hline EMA (kcal/kg) & 3745,27 & 3889,04 & 3817,17 & 4036,19 & 3980,40 & 4008,30 & 3912,73 \\
\hline
\end{tabular}

(1) 32 dias de idade.

(2) 50 dias de idade.

\section{CONCLUSÕES}

De modo geral, a alimentação diferenciada das porcas e dos leitões ou a idade dos animais, não interferiram de maneira decisiva nos coeficientes de digestibilidade da soja semi-integral extrusada.

Esse produto revelou ter grande viabilidade de utilização nas rações de leitões na fase inicial, no que se refere, principalmente, ao conteúdo energético, apresentando altos níveis de energia digestível e metabolizável, quando comparado ao farelo de soja.

\section{REFERÊNCIAS}

ADAMS, K.L.; JENSEN, A.H. Comparative utilization of in-seed fats and the respective extracted fats by the young pig. Journal Animal Science, v. 59, p. 1557-1566, 1984.

ATTEH, J.O.; LEESON, S. Effect of increasing dietary fat, calcium and phosphorus levels on pigs. Canadian Journal Animal Science, v. 63, p. 699-705, 1983.

BELLAVER, C.; COTREFAL, G.; GRECCO, M. Soja integral: processamento e uso. Alimento Animal, v.7, p.28-30, 2002

BERTOL, T.M.; MORES, N.; LUDKE, J.V.; FRANKE, M.R. Proteínas da soja processadas de diferentes modos em dietas para desmame de leitões. Revista Brasileira de Zootecnia, v. 30, n.1, p. 150-157, 2001.

CASTILLO, W.L.; KRONKA, R.N.; BARBOSA, H.P.;
THOMAZ, M.C.; GOMES DA SILVA, L.P.; RIBEIRO, P.R.; CARVALHO, L.E.; TRINDADE NETO, M.A. Efeito da utilização da soja semi-integral extrusada sobre o desempenho e as características das carcaças de suínos. ARS Veterinária, v.17, n.2, p.137-143, 2001.

CERA, K.R.; MAHAN, D.C.; CROSS, R.F.; REINHART, G. A.; Whitmoyer, R. E. Effect of age, weaning and postweaning diet on small intestinal growth and jejunal morphology in young swine. Journal Animal Science, v. 66, p. 574-584, 1988a.

CERA, K.R.; MAHAN, D.C.; REINHART, G.A. Effect of dietary dried whey and corn oil on weaning pig performance, fat digestibility and nitrogen utilization. Journal Animal Science, Champaign, v. 66, p. 1438$1445,1988 b$.

CERA, K.R.; MAHAN, D.C.; REINHART, G.A. Weekly digestibility of diets supplemented with corn oil, lard or tallow by weanling swine. Journal Animal Science, v. 66 , p. 1430-1437, 1988c.

ENRIGHT, K.L.; KIM, I.; HANCOCK, J.D.; REDY, P.G.; KENNEDY, G. A.; HINES, R. H. Nutrient digestibility and utilization in extruded and low-trypsin inhibitor soybeans for weanling pigs. Journal Animal Science, v. 71 (Suppl. 1), p. 157, 1993.

FRIESEN, K.G.,; NELSSEN, J.L.; GOODBAND, R.D.; BEHNKE, K.C.; KATS, L.J. The effect of moist extrusion of soy products on growth performance and nutrient utilization in the early-weaned pig. Journal Animal Science, v. 71, p. 2099-2109, 1993.

HANCOCK, J.D.; LEWIS, A.J.; JONES, D.B.; 
GIESEMANN, M.A.; HEALY, B.J. Processing method affects the nutritional value of low-inhibitor soybeans for nursery pigs. Kansas: Kansas State University. Swine Day Report, p. 52-55, 1990.

HANCOCK, J.D.; LEWIS, A.J.; REDDY, P.G.; JONES, D.B.; GIESEMANN, M.A. Extrusion processing of lowinhibitor soybeans improves growth performance of nursery pigs fed protein-adequate diets. Kansas: Kansas State University. Swine Day Report, p. 40-43, 1991.

HENRIQUE, A.P.F.; THOMAZ, M.C.; KRONKA, R.N. Digestibilidade da soja integral extrusada para leitões na fase inicial. ARS Veterinária, v. 13, p. 68-74, 1997.

LI, D.F.; THALER, R.C.; NELSSEN, J.L.; HARMON, D.L.; ALLEE, G. L.; WEEDEN, T.L. Effect of fat sources and combinations on starter pig performance, nutrient digestibility and intestinal morphology. Journal Animal Science, v. 68, p. 3694-3704, 1990.

MATTERSON, L.D.; POTTER, L.M.; STUTZ, M.W. The metabolizable energy of feed ingredients for chickens. Research Report, v. 7, p. 3-11, 1965.

MENDES, W.S.; SILVA, I.J.; FONTES, D.O.; RODRIGUEZ, N. M.; MARINHO, P. C.; SILVA, F. O.; AROUCA, C. L. C.; SILVA, F. C. O. Composição química e valor nutritivo da soja crua e submetida a diferentes processamentos térmicos para suínos em crescimento. Arquivo Brasileiro de Medicina Veterinária e Zootecnia, v.56, n.2, p.207-213, 2004.

MOREIRA, I.; ROSTAGNO, H.S.; COELHO, D.T.;
COSTA, P. M. A.; TAFURI, M. L. Determinação dos coeficientes de digestibilidade, valores energéticos e índices de controle de qualidade do milho e soja integral processados a calor. Revista da Sociedade Brasileira de Zootecnia, v. 23, p. 916-929, 1994.

NATIONAL RESEARCH COUNCIL. Nutrient Requirement of Swine. 10.ed. Washington,DC: National Academic Science, 1998. 189 p.

PEKAS, J. Versatile swine laboratory apparatus for physiologic and metabolic studies. Journal Animal Science, v. 27, p. 1303-1306, 1968.

SOHN, K.S.; MAXWELL, C.V.; SOUTHERN, L.L.; BUCHANAN, D S. Improved soybean protein sources for early-weaned pigs. II: Effects on ileal amino acid digestibility. Journal Animal Science, v. 72, p. 631-637, 1994.

STEEL, R.G.D.; TORRIE, J.H. Principles and procedures of statistics. 2 ed. Nova York, McGraw Hill, 1980. 633p.

TOKACH, M.D.; CORNELIUS, S.G.; RUST, J.W. The appropriate level of fat addition to high milk product diets for the early weaned pigs. Journal Animal Science, v. 67 (Suppl. 1), p. 231, 1989.

TURLINGTON, W.H.; POLLMANN, D.S.; ENDRES, J.G.; COALSON, J.A. Soy protein concentrates: An alternative to milk proteins. Feedstuffs, n.3, p. 16-18, 1990.

Protocolado em: 18 maio 2011. Aceito em 29 jun. 2012. 